\title{
The prevalence of drug use among university students in St. Petersburg, Russia
}

\author{
Larissa A. Tsvetkova, Natalia A. Antonova \\ St. Petersburg State University, St. Petersburg, Russia
}

\begin{abstract}
Over the last decade, the problem of young people's health has been among the most important and complicated ones for Russian society; these problems affect not only young children but also students in higher education institutions. The low level of physical and psychological health of young people has become an alarming characteristic of the demographic situation in modern Russia.

This study was carried out at the State University of St. Petersburg, which is one of the largest higher education institutions in Russia. The university consists of many academic departments, and thus it is possible to study the health-related behavior of students with different professional backgrounds.

The results show that drug use among students in Russia still remains relatively rare and episodic; in most cases, students use "light" drugs and thus have both slow rates of developing an addiction and an alternative but successful socialization in modern youth subculture. Such drugs are also not generally associated with significant health risks.
\end{abstract}

Keywords: risk behavior, drug use, university students, social aspects of drug use

According to numerous analytical surveys, the health of the Russian population tends to be the primary source of both economic and political threats in modern Russia. In this regard, the health of young people is a key factor in the promotion and preservation of the health of the population as a whole because it determines the overall level of population health in the short term.

The incidence of various diseases in Russia's population is unevenly distributed among different social and demographic groups. This distribution strongly correlates with each group's age. In other words, the incidence of specific diseases among young people differs from that of the middle-aged or elderly (Gurvich, 1999). As a result, we have very specific forms of youth behavior that help increase the risk of diseases within this group. The "risk" behavior among present-day Russian youth also varies directly with geographical location (Gurvich et al., 2005).

University students are not the most susceptible to substance use among different youth groups. However, about 75\% of high school graduates now become university students in Russia (Tsvetkova, 2012). Thus, university students are an important group with regard to studying the health-related behavior of young peo- 
ple. Higher education institutions (universities) are the ideal environment for the implementation of prevention programs.

Moreover, young people constitute the most dynamic part of society. Hence a comprehensive empirical evaluation of risky behavioral practices that are highly relevant to students, such as alcohol consumption, drug use, and sexual promiscuity, is the only way to ensure the effectiveness of prevention programs. Sexual promiscuity is a particularly serious threat given the present dynamics of the HIV/ AIDS epidemic in Russia. Despite considerable efforts in the area of HIV prevention that have been made since the beginning of the epidemic, Russia remains one of the few countries in Europe where the HIV epidemic continues to spread (UNAIDS/WHO, 2011).

Health-related behavior models should determine the content of and directions and methods for implementing prevention programs among young people. However, given the fact that a preliminary research stage and an evaluation are rarely included in prevention projects and given also the lack of information on the stability of beneficial effects over time, the potential for successful replication of prevention programs is not high.

For example, in 2011 we (along with some colleagues) searched PubMed, the electronic catalogue of the National Library of Russia, and studied 187 Internet pages in order to find descriptions of effective HIV programs in Russia (Makhamatova, Levina, Eritsyan, \& Antonova, in press). The texts had to have been published (dated) between January 1, 2007, and January 1, 2010, and had to have been written in Russian or in English. One hundred eleven full texts were identified. Only 43 papers $(38.7 \%)$ contained information on the evaluation of interventions. Our systematic review showed that the most frequent target population groups were the general population (39.5\%) and HIV-positive people (25.6\%).

Jessor and Jessor (1977) in their theory of problem behavior suggest that risk behavior is part of the normal development of the adolescent and, therefore, is purposeful, meaningful, and functional behavior. It helps adolescents to achieve acceptance and respect among peers, as well as a certain degree of autonomy from the family; to cope with anxiety, frustration, and fear of failure; and to demonstrate to oneself and significant others one's own identity, maturity, and success in making the transition to adulthood. Thus, risk behavior, such as the use of psychoactive substances, can facilitate a young person's ability to cope with the stress factors that accompany this period of life (Johnston, O’Malley, \& Bachman, 2000).

Overall, researchers note that the number of risky behavioral practices among young people increases after they leave school (Galambos \& Leadbeater, 2000). However, both Russian and foreign studies show that, in general, admission to university is a protective factor against drug use.

\section{Methods}

In 2006, with the financial support of the Ministry of Education and Science of the Russian Federation, the Department of Psychology of St. Petersburg State University (SPSU) started a "model" project under the supervision of Professor I. Gurvich aimed at maintaining and promoting students' health.

The main goals of the research project were (a) to study risk behavior among students at SPSU and (b), based on the results of such a study, to further develop 
and implement effective prevention programs in the field of health in order to reduce the incidence of risk behavior among students.

The project included the following stages: a research stage that aimed at setting the priorities as well as defining the most effective preventive strategies for a multipurpose prevention program; implementation of a preventive program with its content differentiated according to the type of professional specialization as well as the curriculum; a final stage, during which the effectiveness of the prevention program was evaluated.

\section{Questionnaire}

To evaluate the health-related behavior of students, a questionnaire was developed that contained the following kinds of questions: consumption of drug and nondrug substances; behavior related to contracting infectious and noninfectious chronic diseases as well as to elevating the risk of injury; environmental health-damaging factors; health condition; coping with strain; eating habits; sports activities; work-rest ratio; medical aid and intervention measures; participation in prevention programs.

A pilot cluster-sample study was conducted in the spring of 2006 with the aim of developing a final version of the questionnaire. First, two natural science departments (Mathematics and Mechanics, and Biology and Soil) and two human science departments (Economics and Journalism) were randomly selected. Second, training groups were selected proportionally among students in the 1 st to the 4 th years of study. The final sample consisted of 110 people. The questionnaire was corrected after data collection during the pilot study. The final version of the questionnaire had 201 questions.

According to international practice, the level of drug use among the students in our sample was measured across the main groups of drug and nondrug substances and by types of prevalence:

- lifetime prevalence: consumption of psychoactive substances not prescribed by a doctor during any period of the respondents' lives

- previous-year prevalence: consumption during the 12-month period prior to the survey

- previous-month prevalence: consumption during the 30-day period prior to the survey

- previous-day prevalence: consumption during the 24-hour period prior to the survey

\section{Sample selection}

Full-time students from the majority of the departments at SPSU (18 departments out of 19), representing all years of study from the 1 st to the 4 th, were the subjects of the study. The students of the School of Management were not interviewed because its administration refused to cooperate. The sampling for the study was graded: during the first stage continuous sampling was performed across the faculties of SPSU; during the second one continuous sampling took place across the 1st to the 4 th years of study. Because the study had to have some practical outcomes, students in the last (5th) year of study - those who were to graduate the year following the 
poll-were not included in the target group. During the third stage of sampling, a survey was performed in a proportional, nonsystematic manner: 25 students from each year of study out of those present on the day of the survey were interviewed. The overall sample was representative as its final size was 1,690 people.

Primary data collection was carried out via group interviews. The survey as such was conducted in classrooms during an ordinary school day. The survey was anonymous.

\section{Data analysis}

Data on 1,477 respondents were used for statistical analysis; 213 questionnaires that had been filled in incorrectly ( $12.6 \%$ of the final sample) were excluded from the whole set when checking the collected material and entering the data. The final aggregate size of the sample was $87.4 \%$ of the planned one.

Mathematical statistical processing of the data involved calculating simple distributions and central tendency measures $(\mathrm{M}, \mathrm{Me}, \delta, \mathrm{Q} / 2)$ with the help of the SPSS 13.0 software package. A correlation analysis was also performed. To evaluate the correlation of parameters on nominative scales, the Cramer's V correlation coefficient (based on Pearson's chi-squared statistic) was used. The final model included only statistically significant $(p \leq 0.05)$ correlates. We present multivariate-adjusted odds ratios (ORs) and corresponding 95\% confidence intervals (CIs) for the variables.

In this article, some research data will be presented, including the gender breakdown of drug-use prevalence among students at SPSU.

\section{Results}

As for the demographics of the sample, two-thirds of the respondents were female, and one-third were male. The respondents were in most cases 19 tyears old or younger (59.2\%) or 20 to 24 years old (40.1\%); respondents of older ages represented less than $1 / 100$ of the sample.

Each department participating in the project was represented by a $3.5 \%-7.0 \%$ share of the sample. First-year students constituted $28 \%$ of the sample; secondyear students, $26 \%$; third-year students, $25 \%$; and fourth-year students, $21 \%$. The number of respondents decreases slightly with increased years of study because, on the one hand, senior students attend fewer classes in general and, on the other, they are enrolled in fewer general lectures and more specialized courses than students in the first three years of study.

\section{Patterns of drug use}

One-fifth of the students at SPSU reported using drugs or similar substances not prescribed by a doctor at least once in their life.

According to the self-reports of the respondents, the types of drug substances they had used during their lifetimes were as shown in Table 1.

Clearly, cannabis derivatives were the most widely used drugs among students; their use was reported by $95 \%$ of the respondents who had ever tried any such substance. Every third respondent had used stimulants (chifir: exceptionally strong tea, ephedrine, amphetamines, etc.); every fifth student had used analgesics (Tramal, 
Table 1. Types of Drugs Used over Lifetime

\begin{tabular}{lccc}
\hline Characteristics & $\begin{array}{c}\text { Male No. (\%) } \\
\text { (Total = 115) }\end{array}$ & $\begin{array}{c}\text { Female No. (\%) } \\
\text { (Total = 207) }\end{array}$ & $\begin{array}{c}\text { Whole sample No. (\%) } \\
\text { (Total = 322) }\end{array}$ \\
\hline Drugs used & & & \\
Analgesics (pain relievers) & $19(16.5)$ & $43(20.8)$ & $62(19.3)$ \\
Atropine-type drugs & $8(7.0)$ & $6(2.9)$ & $14(4.3)$ \\
Inhalants & $3(2.6)$ & $1(0.5)$ & $4(1.2)$ \\
Hallucinogens & $25(21.7)$ & $26(12.6)$ & $51(15.8)$ \\
Stimulants & $44(38.3)$ & $53(25.6)$ & $97(30.1)$ \\
Sleeping pills & $7(6.1)$ & $7(3.4)$ & $14(4.3)$ \\
Cannabis derivatives & $109(94.8)$ & $197(95.2)$ & $306(95.0)$ \\
Cocaine & $16(13.9)$ & $19(9.2)$ & $35(10.9)$ \\
Opiates & $7(6.1)$ & $8(3.9)$ & $15(4.7)$ \\
\hline
\end{tabular}

Note. Numbers do not add to totals because respondents could report use of more than one type of drug.

paracetamol, Analgin); $15.8 \%$ of the respondents had tried hallucinogens (LSD, "mushrooms"). Use of other substances was slightly less widespread: cocaine had been used by one-tenth of the respondents; opiates (opium, morphine, heroin), by 4.7\%; atropine-type drugs (Benadryl, Astmatol, Cyclodol) and sleeping pills, each by $4.3 \%$ of the respondents. The least-used drugs were household chemicals (inhalants such as glue, paint remover); they were used by $1.2 \%$ of the respondents who had used any drug and/or toxic substance in their lives.

Those students who had used drugs during the 12 months before the survey constituted two-thirds (68.6\%) of all respondents who reported drug use.

Of the respondents who reported drug-use experience, $23.6 \%$ had used drug substances during the 30-day period preceding the survey. About $8 \%$ of those students who had tried drugs also used them on the day preceding the survey. This finding suggests that these students are the most likely to develop a drug addiction later.

Table 2. Lifetime Prevalence of Drug Use among the Study Population

\begin{tabular}{|c|c|c|c|c|c|c|}
\hline Characteristics & $\begin{array}{l}\text { Male No. }(\%) \\
\text { (Total = 460) }\end{array}$ & $\begin{array}{c}\text { Female No. }(\%) \\
(\text { Total = 1017) }\end{array}$ & $p$ value & $\begin{array}{c}\text { Cramer's } \\
\text { V }\end{array}$ & $\begin{array}{l}\text { Odds } \\
\text { ratio }\end{array}$ & 95\% CI \\
\hline \multicolumn{7}{|l|}{ Drug use during lifetime } \\
\hline Have used drugs & $115(25.0)$ & $207(20.4)$ & \multirow{2}{*}{$\leq 0.05$} & \multirow{2}{*}{0.052} & \multirow{2}{*}{1.30} & 1.01 \\
\hline Have never used drugs & $345(75.0)$ & $810(79.6)$ & & & & 1.69 \\
\hline \multicolumn{7}{|c|}{ Use of stimulant-type drugs during lifetime } \\
\hline Have used & $44(38.3)$ & $53(25.6)$ & \multirow{2}{*}{$\leq 0.05$} & \multirow{2}{*}{0.132} & \multirow{2}{*}{0.56} & 0.34 \\
\hline Have never used & $71(61.7)$ & $154(74.4)$ & & & & 0.91 \\
\hline \multicolumn{7}{|c|}{ Use of hallucinogen-type drugs during lifetime } \\
\hline Have used & $25(21.7)$ & $26(12.6)$ & \multirow{2}{*}{$\leq 0.05$} & \multirow{2}{*}{0.120} & \multirow{2}{*}{0.52} & 0.28 \\
\hline Have never used & $90(78.3)$ & $181(87.4)$ & & & & 0.95 \\
\hline
\end{tabular}

Note. Numbers may not add up because of missing data. 
The statistical analysis revealed considerable variations in the prevalence of drug use by males and females both on a lifetime basis $(p \leq 0.05)$ (Table 2$)$ and on a monthly basis $(p \leq 0.001)$ (Table 3 ): both prevalences were found to be significantly higher for males. No variations were found in yearly and daily prevalence.

More than half the respondents (56.2\%) among those who had used drugs or similar substances did it for the first time at the age of 17-19 years, while a third first did it at the age of 14-16 years. Every tenth student among those who had ever used drugs had his/her first such experience at the age of 20-25 years. A number of respondents tried drugs for the first time when they were under 14 (3.4\%). Gender differences on this indicator has been not statistically significant (Table 3).

Considerable differences between males and females in lifetime prevalence were revealed in the use of such drugs as stimulants and hallucinogens $(p \leq 0.05)$ (Table 2). Females used these drugs much more rarely during their lifetimes than did their male classmates. With regard to other drug substances, no gender variations were found in lifetime prevalence.

Table 3. Age of First Drug Use; Yearly, Monthly, Daily Prevalence of Drug Use; Social Problems with Drug Use; Have Friends Who Use Drugs

\begin{tabular}{|c|c|c|c|c|c|c|}
\hline Characteristics & $\begin{array}{l}\text { Male No. (\%) } \\
\text { (Total = 115) }\end{array}$ & $\begin{array}{l}\text { Female No. }(\%) \\
(\text { Total = 207) }\end{array}$ & $p$ value & $\begin{array}{c}\text { Cramer's } \\
\text { V }\end{array}$ & $\begin{array}{l}\text { Odds } \\
\text { ratio }\end{array}$ & $95 \% \mathrm{CI}$ \\
\hline \multicolumn{7}{|l|}{ Age of first use (years) } \\
\hline$\leq 7$ & $0(0.0)$ & $1(0.5)$ & \multirow{6}{*}{0.529} & \multirow{6}{*}{-} & \multirow{6}{*}{-} & \multirow{6}{*}{-} \\
\hline $8-10$ & $1(0.9)$ & $1(0.5)$ & & & & \\
\hline $11-13$ & $5(4.3)$ & $3(1.4)$ & & & & \\
\hline $14-16$ & $39(33.9)$ & $62(30.0)$ & & & & \\
\hline $17-19$ & $60(52.2)$ & $121(58.5)$ & & & & \\
\hline $20-25$ & $10(8.7)$ & $19(9.2)$ & & & & \\
\hline \multicolumn{7}{|c|}{ Drug use during the 12 months before the survey } \\
\hline Have used & $82(71.3)$ & $139(67.1)$ & \multirow{2}{*}{0.441} & \multirow{2}{*}{-} & \multirow{2}{*}{-} & \multirow{2}{*}{-} \\
\hline Have not used & $33(28.7)$ & $68(32.9)$ & & & & \\
\hline \multicolumn{7}{|c|}{ Drug use during the 30 days before the survey } \\
\hline Have used & $39(33.9)$ & $37(17.9)$ & \multirow{2}{*}{0.001} & \multirow{2}{*}{0.181} & \multirow{2}{*}{2.36} & \multirow{2}{*}{$1.40,3.99$} \\
\hline Have not used & $76(66.1)$ & $170(82.1)$ & & & & \\
\hline \multicolumn{7}{|c|}{ Drug use during the day before the survey } \\
\hline Have used & $12(10.4)$ & $14(6.8)$ & \multirow{2}{*}{0.247} & \multirow{2}{*}{-} & \multirow{2}{*}{-} & \multirow{2}{*}{-} \\
\hline Have not used & $103(89.6)$ & $193(93.2)$ & & & & \\
\hline \multicolumn{7}{|c|}{ Social problems such as being arrested for drug use } \\
\hline Have been arrested & $5(4.3)$ & $1(0.9)$ & \multirow[b]{2}{*}{0.05} & \multirow[b]{2}{*}{0.115} & \multirow[b]{2}{*}{-} & \multirow[b]{2}{*}{-} \\
\hline $\begin{array}{l}\text { Have never been } \\
\text { arrested }\end{array}$ & $110(95.7)$ & $206(99.1)$ & & & & \\
\hline \multicolumn{7}{|c|}{ Have friends who have used drugs } \\
\hline Have & $160(34.8)$ & $298(29.3)$ & \multirow{2}{*}{0.05} & \multirow{2}{*}{0.055} & \multirow{2}{*}{1.287} & \multirow{2}{*}{$1.02,1.63$} \\
\hline Don't have & $300(65.2)$ & $719(70.7)$ & & & & \\
\hline
\end{tabular}

Note. Numbers may not add up because of missing data. 
The yearly prevalence of analgesic use varied based on gender. About $17.0 \%$ of the females used analgesics during the previous year, compared with $4.0 \%$ of the male students $(p \leq 0.01)$ (Table 4$)$. Taking into account the fact that a number of legal substances are also classified as analgesics, we can assume that the reason for this difference lies in the "medical consumption" of this type of psychoactive substance among females, who use such drugs as a medicine to cope with algetic states of a different nature.

Table 4. Gender Differences in Analgesic Use During the 12 Months Preceding the Survey

\begin{tabular}{|c|c|c|c|c|c|c|}
\hline Characteristics & $\begin{array}{c}\text { Male No. }(\%) \\
(\text { Total = 82) }\end{array}$ & $\begin{array}{c}\text { Female No. }(\%) \\
(\text { Total = 139) }\end{array}$ & $p$ value & Cramer's V & $\begin{array}{l}\text { Odds } \\
\text { ratio }\end{array}$ & $95 \% \mathrm{CI}$ \\
\hline
\end{tabular}

Use of analgesic-type drugs during the 12-month period before the survey

$\begin{array}{lccllll}\text { Have used } & 3(3.7) & 23(16.5) & \leq 0.01 & 0.193 & 5.22 & 1.52,17.98 \\ \text { Have never used } & 79(96.3) & 116(83.5)\end{array}$

Gender variations were also revealed in the daily prevalence of drug use among the students. Thus, exactly one half $(50.0 \%)$ of the male students used stimulants on the day before the survey compared with $7.1 \%$ of the females $(p \leq 0.05)$ (Table 5).

Table 5. Gender Differences in Stimulant Use on the Day Before the Survey

\begin{tabular}{|c|c|c|c|c|c|c|}
\hline Characteristics & $\begin{array}{c}\text { MaleNo. }(\%) \\
(\text { Total = 12) }\end{array}$ & $\begin{array}{l}\text { Female No. }(\%) \\
\quad(\text { Total }=14)\end{array}$ & $p$ value & Cramer's V & $\begin{array}{l}\text { Odds } \\
\text { ratio }\end{array}$ & $95 \% \mathrm{CI}$ \\
\hline \multicolumn{7}{|c|}{ Use of stimulant-type drugs on the day before the survey } \\
\hline Have used & $6(50.0)$ & $13(92.9)$ & \multirow{2}{*}{0.05} & \multirow{2}{*}{0.482} & \multirow{2}{*}{0.077} & \multirow{2}{*}{$0.01,0.79$} \\
\hline Have not used & $6(50.0)$ & $1(7.1)$ & & & & \\
\hline
\end{tabular}

\section{Social aspects of drug use}

the study covered such social aspects of drug use as drug environment and negative social outcomes. Every third student at SPSU reported constant drug use among his/her friends or acquaintances. Male students had considerably more drug user friends in their close social environment than did females $(p \leq 0.05)$ (Table 3 ).

Some negative outcomes of drug use were as follows:

- Almost every tenth student who used drugs stated that his/her health problems stemmed from drug use.

- Every twentieth student reported conflicts with parents, loss of old friends, and financial hardships because of drug use.

- Less frequent were such problems as the break-up of close relationships (3.1\%), being arrested by the police (1.9\%), needing medical help (1.2\%), losing a job or giving up studies (1.2\%). Statistically, as the results of the study show, drug use by males leads much more frequently to arrest than does drug use by females (Table 3 ). These data testify to higher rates of criminalization caused by drug use among male students than among females. 


\section{Discussion}

An objective estimation of the health characteristics of Russian students is hindered by a number of grave technical problems. The statistical data are fragmented and incomplete, a result of both the general state of national health statistics in Russia and by some particularities of providing health services to university students. Still fewer data on health behavior among students can be found in the specialized literature in the Russian language.

The results of our previous research on drug use among students showed clearly that SPSU students live in a city where there is widespread drug use and where drugs have become part of the youth subculture (Gurvich et al., 2005). Generally drugs in modern Russia are used mainly by younger people, more precisely by those in the 25 years and younger age group. But compared with other youth groups, students cannot be said to be the most "endangered" by drug addiction.

Each of the types of prevalence in our study has certain clinical implications.

The results of the study confirm the data collected earlier in a survey conducted in 2002 in the Psychology Department of SPSU and show that lifetime prevalence of drug use among students has decreased significantly since then, from $29.3 \%$ to $21.8 \%(\chi 22=21.1, p \leq 0.001)$. A decline in the rates of drug use over the period from 2002 to 2006 was also recorded in a study by American colleagues (Johnston, O’Malley, Bachman, \& Schulenberg, 2007).

The lifetime prevalence of drug use among male students turned out to be considerably higher than that among female students; this result may speak to the higher social acceptability of drug use among males. Taken as a whole, however, these findings for lifetime drug use are likely to be indicative of a "normal" consumption of psychoactive substances that is quite far from what we might label an addiction.

The findings on yearly prevalence, on the contrary, indicate the early stages of involvement in systematic drug use. Also, gender-related differences were found in one-month prevalence. Monthly drug use was relatively rare; it amounted to $5 \%$ of the total number of students in the sample, but it was considerably higher among male students than among female students. In other words, it is very likely that the male students exhibited the symptoms of a drug-addiction syndrome.

Most of the psychoactive substances the use of which can lead to addiction have an abstinent length of a minimum of one month. Daily drug-use allows us to state with a high probability that this is a form of strong addiction.

Drug use among students still remains relatively rare and episodic and involves the use of "light" drugs in most cases. This use pattern leads both to the slow development of an addiction and to an alternative but successful socialization in modern youth subculture. It is also not associated with significant health risks.

In the present situation in Russia, virtually any sort of drug is easily available, and students live their lives in the "close vicinity" of active drug users from social, territorial, and psychological points of view.

\section{Conclusions}

Antidrug activity has to become one of the main focuses of prevention programs among students. The proportion of intravenous drug users among the interviewed students was relatively low. However, quite a few of them reported using "dirty" 
syringes, which greatly increases the risk of HIV infection. At the same time only a small portion of the students have had HIV blood tests. Hence it appears that it is absolutely necessary to implement all measures of primary and secondary HIV/AIDS prevention among the students, first and foremost HIV blood tests.

The results of the study contribute to the accumulation of statistical data on the prevalence of risk behaviors among students and provide a reliable basis for planning preventive work among students in the field of health protection and promoting healthy behavior.

This study has some limitations. The sample does not represent the whole subpopulation of young people in Russia but only the students of one of the top universities in the country, and drug use is a selection factor that can reduce a young person's chances of getting into university. Therefore, our sample has values on drug use approximating the minimum values within the same territorial and age group

\section{Aknowledgements}

This "model" research project was supported by the Analytical Administrative Target Program "Increasing the research capacity and potential of higher education institutions (2006-2008)" funded by the Russian Federation's Ministry of Education and Science Project: "Development of scientifically grounded principles and methods for the development and implementation of programs aimed at promoting a healthy lifestyle, preventing noninfectious diseases, and ensuring the safety of students."

\section{References}

Galambos, N.L., \& Leadbeater,B.J.(2000). Trendsinadolescent research for thenew millennium. International Journal of Behavioral Development, 24, 289-294. doi: 10.1080/01650250050118268

Gurvich, I. N. (1999). Social psychology of health. St. Petersburg: Saint-Petersburg State University. Gurvich, I. N., Bereznikov, A. A., Nikiforov, G. S., Lyskov, B.D., Grankaya, Y.V., Tsvetkova, L.A., Shaboltas, A.V., Yanicheva, T.G., Rusakova, M.M., Hlopushin R.G., Spirina, V.L., Fyodorova, D.A., Kukushkina, Y.A. (2005). The state of the drugs problem in University. In I. N. Gurvich (Ed.). St. Petersburg: Saint-Petersburg State University.

Jessor, R., \& Jessor, S. L. (1977). Problem behavior and psychological development: A longitudinal study of youth. New York: Academic Press.

Johnston, L.D., O'Malley, P.M., \& Bachman, J. G. (2000). Monitoring the Future national survey results on drug use, 1975-1999. Volume 1: Secondary school students (NIH Publication 004802). Rockville, MD: National Institute on Drug Abuse.

Johnston, L. D., O’Malley, P. M., Bachman, J. G., \& Schulenberg, J. E. (2007). Monitoring the Future national survey results on drug use, 1975-2006. Volume 2: College students and adults ages 19-45 (NIH Publication 07-6206). Bethesda, MD: National Institute on Drug Abuse.

Makhamatova, A.F., Levina, O.S., Eritsyan, K.Y., \& Antonova, N.A. (in press). The psychological component of effective HIV prevention programs in Russia. Vestnik Sankt-Peterburgskogo universiteta [The St. Petersburg University Herald], 12.

Tsvetkova, L. A. (2012). Social psychology of drug use among students (2nd ed.). St. Petersburg: Saint-Petersburg State University.

UNAIDS/WHO (2011). HIV/AIDS in Europe and Central Asia. 2011 progress report. Retrieved from http://www.unaids.ru/sites/default/files/eca_regional_report_on_ua_to_hiv_ programsl.pdf 